\title{
Homöopathie beim atopischen Ekzem
}

Zur Wirksamkeit der Homöopathie bei atopischem Ekzem lagen bisher zwar eine Reihe von Kasuistiken, aber keine kontrollierten Therapiestudien vor. Jetzt wurde eine solche Studie vorgestellt.

- Deutsche Forscher randomisierten 24 Patienten, die an atopischem Ekzem litten, in zwei Gruppen. Nach vier Wochen ohne jegliche Therapie erhielten sie 32 Wochen lang entweder individualisiert verschriebene Homöopathika oder Placebos.

Als Hauptzielparameter wurde ein validierter Symptomscore herangezogen. Dieser zeigte bei Therapieende keine Vorteile für die Verumgruppe. Ebenso fanden sich bei den sekundären Zielparametern keine signifikanten Gruppendifferenzen. Die Autoren

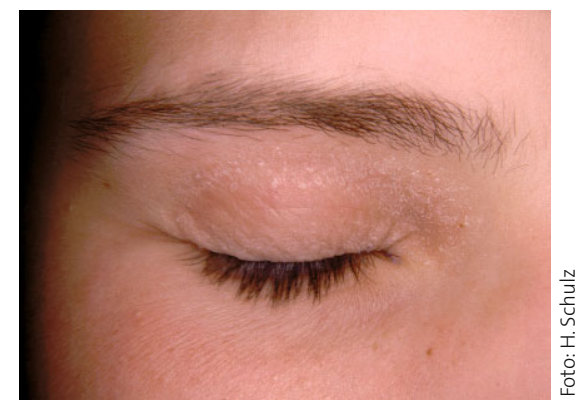

Atopisches Lidekzem bei 20-jähriger Patientin.

schließen daher, dass „individualisierte homöopathische Arzneien ... keinen über Placebo hinausgehenden Effekt" aufweisen.

KOMMENTAR: Alle Homöopathen, die ich kenne, sind überzeugt, das atopische Ekzem effektiv behandeln zu können. Trotz dieser weitverbreiteten Annahme gab es bislang keine Überprüfung der Richtigkeit dieser These. Die vorliegende Studie scheint gut angelegt zu sein, sie leidet jedoch unter der kleinen Fallzahl, die im Studienverlauf noch weiter absank - zehn Patienten brachen die Studie vorzeitig ab (meist wegen fehlender Wirksamkeit). Daher könnte man meinen, wie die Autoren das tun, dass die Studie zu klein war, um einen vorhandenen Effekt darzustellen. Dies scheint jedoch eher unwahrscheinlich: Ein recht deutlicher Trend impliziert sogar die Überlegenheit von Placebo über Homöopathie. Fazit: Die wohl wahrscheinlichste Erklärung der Daten ist, dass Homöpathie beim atopischen Ekzem nichts bringt.

E. ERNST =

- J. Siebenwirth et al.

Wirksamkeit einer klassisch-homöopathischen Therapie bei atopischem Ekzem. Forsch. Komplementmed. 16 (2009) 315-323

\section{Achtung:}

\section{Hier muss der \\ Dummy durch \\ eine Anzeige \\ ersetzt werden !!}

